\title{
Researching through unfamiliar practices
}

\begin{abstract}
This paper draws upon my first experience of processing a bird into meat to suggest that growing geographical interest in practices might benefit from a focus as much on the experiences and accounts of first-time practitioners as those of established practitioners.
\end{abstract}

\section{Keywords}

practices, affective, method, materiality, becoming, hybrid

\section{Introduction}

Methodological engagement in practices is all the rage these days, with a growing number of auto-ethnographic accounts of practical doings in artistic practice, marine videography, distance running, cycling, horse riding and poetry, to name just a few ${ }^{\mathrm{i}}$. Consistent with demands for such accounts to be informed by proficient practice on the part of the researcheri ${ }^{\mathrm{ii}}$, several of the authors cited above had obtained formal qualifications or practised competitively or professionally. Nonetheless, researchers also frequently focus on instances that fall short of, or conflict with, their established experience of that practice in some way, emphasising instances when things go awry 
and highlighting challenges such as injury and rehabilitation, or accomplishing new skills.

Often, this emphasis reflects efforts to articulate embodied sensation or affective experience $^{1}$, potentially brought into greater awareness as unfamiliar challenges disrupt otherwise unthinking practices developed through extensive activity. With sustained practice, practitioners are thought to attune to or synchronise with the materials and environment of their practice, enabling them to anticipate practice regularities prereflectively, generating proficient performance without deliberate cognition ${ }^{\mathrm{iii}}$. In proficient practice, a contrast with that sensory synchronisation- - jolting the practitioner out of the familiar - is thought to aid access to the affective through comparison, as in my own proposal (details removed for peer review) of deliberately unsettling established practices as a legitimate research method. However, in this paper, I suggest something different — namely, that research undertaken through unfamiliar practices might also be of disciplinary interest.

If some senses are heightened as we become familiar with a given practice, that same sensory specialisation potentially leaves other aspects of the practice overlooked through our relative desensitisation to them. In thinking about cultural geography and practice, then, what insights might arise from the asynchronous practice and relative anticipatory incapability of a first-time practitioner? How might this insight inform our understandings of the spatial, social, and subjective more broadly? 
I explore these issues through my own first-time experience of processing meat birds for consumption. While not initially undertaken for academic purposes, this experience is examined here as a condensed version of a longer account written immediately after I processed the birds to inform my academic thinking on materiality, with extracts from the original account (in italics) woven into more recent analysis.

In 2011, I was considering introducing chickens to my back garden. First, though, I needed to determine whether I could do what would be necessary to eat my birds, as I intended. To this end, I purchased two pheasants, already dead but in full feather and with innards still inner, on which to practise plucking, gutting and jointing. Of particular interest are two elements that impacted powerfully upon me: 1) the sharp contrast between different pheasant materialities, and 2) the body parts once parted from their body. Together, these elements generated a sense of erratically textured space in which the textures encountered fluctuated frequently, unexpectedly and conflictingly. Rather than progressing smoothly from bird to meat, the pheasant seemed to fluctuate between the two. In contrast to notions of the hybrid as simultaneously incorporating two distinct elements, I conceptualise these instances as chimerical, in which an entity is neither one thing nor another. The impact of these experiences during unfamiliar practice suggests that researchers lacking anticipatory capability might be more rather than less sensitive to certain sensory and affective experiences. 


\section{Feather, flesh, and fluid}

The down was luxuriously soft, and even the larger, firmer flight feathers that swished as I moved the wings enticed tactile engagement. Contrasting sharply with the feathers' gentility were the legs: thin, hard sticks kitted out with a weaponry of talons. As I laid the bird back down the skull's solidity made itself sonorously present. The birds' presence in the kitchen felt far greater than suggested by their size or shape alone.

As I plucked, I found that sometimes tugging in one direction was best and sometimes, another. The larger feathers were trickier, occasionally tearing the skin and releasing fat that yielded a highly unpleasant localized wetness on the bird. The delightful tactility of dry feathers became an equally repulsive clinginess when the feathers were wet, drying into a crusty amalgam of feather and bodily fluid. Occasionally, my hand made inadvertent contact with the increasingly exposed flesh of the bird, driving a cold tacky wedge of sensation into the fluctuating tactility of the process.

Through this increasingly conflicted tactility between pleasurable softness and confronting wetness, clinginess and tackiness, the birds acquired a seemingly unnatural chimerical quality. They resembled — visually and texturally—neither animal nor meat but an inbetweenness of being: a bird-meat-thing. I was unable to relate to it either affectively as animal or purposively as meat. Although I quickly became familiar with the put-put-put of the methodical removal of the feathers, this fledgling synchrony was 
intruded upon by the tacky sensations and weeping fluids, which increased the more I plucked.

This intrusion highlighted both my lack of sensory specialisation and my anticipatory incapacity: I could neither disregard nor predict the intrusions because I lacked any previous experience on which to base my expectations. Both the textural experiences and my affective responses to them became increasingly erratic: the textures that I encountered fluctuated frequently, unexpectedly and conflictingly, generating unfamiliar, confused and aversive sensations. The triadic relationships between flesh, fluid and feather sometimes co-existed peacefully and sometimes clashed brutally in an erratically textured space as wetness eliminated softness, tackiness overpowered wetness, and softness periodically returned.

After I removed the head, feet and wings, their subsequent existence as now-separate items again altered my relations with the bird-meat-thing. Initially I left one wing on the counter, intending to dispose of all the body bits together at the end. A moment later, however, I was so strongly repulsed by the wing that it no longer seemed to be the same thing that I had held in my hand only moments previously. The wing's materiality did not change upon its separation from the bird's carcass: its shape, manipulability and tactility all remained the same. The sensation, though, of holding the wing as a separate thing transformed from pleasurable velvety softness to aversive disgust. The removed wing seemed to have regained its animality even though cognitively and visually the 
pheasant was now closer to meat than bird. In contrast to the liveliness that had initially filled the kitchen, now the pheasant spoke with savage honesty about the "what is no more-ness" of the creature before me and my role in its de/reconstruction. I was brought sharply back to self-awareness at precisely those instants when I was most immediately aware of the pheasant, accentuating the shifting subjectivities of bird and human throughout the process. Despite progressing ever closer to meatness, the pheasant's materialities reasserted its birdness, leaving me unable to shake off its original birdness even as my own actions imposed meatfulness upon it.

\section{Chimerical Instability}

Between the pheasants' start and end states, they hovered in a chimerical state of birdmeat-thing in which they were neither animality nor meatfulness but fluctuated between the two. I recoiled against touching the flesh when the bird remained whole, but also recoiled against touching the feathers once a body part had been removed. Not only did the pheasants' varied materialities impose themselves upon me in rapid and confronting succession, but the same materiality (the feathers) evoked conflicting affective responses in different states of being (wetness versus dryness) and different stages of becoming meat (before versus after removing the wing). The pheasants hovered in the midst of an incomplete process of becoming meat, with the erratic textural experience 
alternately encouraging and impeding that process by manipulating my engagement with the pheasants.

In its chimerical state, the pheasant as meat was 'not yet' and the pheasant as bird was 'not still'. As the pheasant became progressively closer to meat in terms of its form, the pheasant also reinforced its 'not yet meatness' in terms of its material affectivity by seemingly reasserting its birdness. Unlike more familiar ideas of hybridity as the integration of two heterogeneous forms, the chimerical pheasant struggled to sustain two forms as it progressively differentiated the meat from the bird ${ }^{\mathrm{iv}}$. It was in this chimerical state that the pheasants as both bird and meat had maximal impact. Like a Necker cube or face-vase illusion, the bird-meat-thing was not sustainable as one thing before the other thing maximally imposed itself upon me. Bird and meat could not co-exist yet neither could they be sustained alone.

It was the erratically textural nature of the bird's materialities that generated this chimerical quality, and it was my unfamiliarity with the practice of plucking that made me sensitive to this textural erraticism as I had not developed the sensory synchrony necessary to anticipate, disregard or minimise those confronting textural experiences. Seemingly, then, geographical research through unfamiliar practice can supplement research undertaken through proficient practice, due to a lack of sensory specialisation among first-time practitioners. 


\section{Conclusion}

Although I did consider abandoning the task of processing the pheasants, I completed the exercise and have now kept chickens for five years (and yes, I do eat them). Those chimerical elements have themselves become practice regularities, which I anticipate every autumn when processing the chickens. Repeated exposure and sustained practice have removed their impact.

What implications for cultural geography arise from this experience? First, it suggests that the sensory synchrony that comes through sustained practice can render us less rather than more sensitive to certain elements of that practice. Consequently, research conducted through unfamiliar practices might generate new aspects of practice (e.g. chimerical instability) for geographical exploration, due precisely to a lack of anticipatory capability. Second, the concept of chimerical instability itself might inform disciplinary engagement with related concepts (e.g. hybridity) by encouraging reconsideration of the relations between the many and the one in composite concepts. This might contribute to efforts to unsettle notions of static, essentialist spaces, societies and subjects by emphasising their conflicted and unstable nature, and the indiscernibility of transitions between their varied states. Given the contemporary blending of spaces, subjectivities, societies, species and 
technologies in an increasingly interconnected world, it seems timely to develop our disciplinary lexicon for diverse composite forms.

\author{
Notes \\ ${ }^{1}$ I use the term affective broadly here to include emotional, bodily and visceral \\ sensibilities, rather than to distinguish affect from emotion.
}

\title{
References
}

\footnotetext{
'Scalway, 'A patois of patter: Pattern, memory and the cosmopolitan city', Cultural Geographies 13 (2006), pp. 451-7. Hawkins, 'Creative geographic methods: knowing, representing, intervening. On composing place and page', Cultural Geographies 22 (2015), pp. 247-68. Merchant, 'The body and the senses: Visual methods, videography and the submarine sensorium', Body and Society 17 (2011), pp. 5372. Hockey, 'Sensing the run: senses and distance running', Senses and Society 1 (2006), pp. 183-202, Spinney, 'A place of sense: a kinaesthetic ethnography of cyclists on Mount Ventoux', Environment \& Planning D: Society \& Space 24 (2006), pp. 709-32. Game, 'Riding: Embodying the centaur', Body and Society 7 (2001), pp. 1-12. Madge, 'On the creative (re)turn to geography: poetry, politics and passion', Area 46 (2014), pp. 178-85.

ii Lafrenière and Cox, "If you can call it a poem': Toward a framework for the assessment of arts-based works', Qualitative Research 13 (2013), pp. 318-36. Marston and de Leeuw, 'Creativity and geography: toward a politicized intervention', Geographical Review 103 (2013), pp. III-XXVI.
} 
iii Game, pp. 1-12, Spinney, pp. 709-32, Merchant, pp. 53-72.

iv Whatmore, 'Dissecting the autonomous self: Hybrid cartographies for a relational ethics', Environment and Planning D-Society \& Space 15 (1997), pp. 37-53. Whatmore, Hybrid geographies : natures, cultures, spaces (London, SAGE, 2002). 